\title{
Electricity Generation from Low Temperature Sources
}

\author{
N. Galanis, E. Cayer, P. Roy, E.S. Denis and M. Désilets \\ Université de Sherbrooke, Génie mécanique, THERMAUS \\ Sherbrooke QC, Canada, J1K 2R1 \\ Email:nicolas.galanis@usherbrooke.ca
}

(Received December 29, 2008; accepted February 12, 2009)

\begin{abstract}
Power plants using conventional processes and unconventional fluids have a significant potential for the valorization of low and medium temperature renewable energy sources as well as waste heat from industrial, commercial or institutional installations. This review paper describes some prototypes of such power plants and summarizes some of the relevant scientific and technical literature. An analysis based on the first and second laws of thermodynamics and basic heat transfer relations is used to illustrate the operational limits and performance characteristics of these power plants.
\end{abstract}

Keywords: waste heat, solar energy, geothermal energy, organic Rankine cycles, trans-critical cycles, cycles with binary mixtures, prototypes, thermodynamic analysis, literature review

\section{INTRODUCTION}

The availability of abundant quantities of energy is an essential condition for the well-being and development of our modern industrial societies. As the population and economic activity increase, the global consumption of energy rises continuously. The principal primary energy sources which are used to satisfy this ever-increasing demand in all the economic sectors are fossil fuels. Although available in large quantities, they are neither infinite nor renewable. Furthermore, the conversion of their chemical energy into useful work by combustion and thermal engines (which is almost the only method used for their exploitation) is subject to the fundamental laws of thermodynamics which severely limit the efficiency of such systems and results in undesirable side effects (greenhouse gases, urban smog, thermal pollution and acidification of lakes and rivers, etc.). It is therefore imperative to seek and adopt alternate renewable energy sources as well as methods which improve the conversion efficiency and diminish the negative impacts of fossil fuelled engines.

One way of increasing the performance and decreasing the environmental impact of stationary thermal engines is by recuperating and utilizing low grade thermal energy in combustion gases. Traditional examples of such applications are the heating of the combustion air supplied to the boilers of steam plants by the flue gases and the cogeneration installations using the exhaust gases of a gas turbine plant to produce steam for industrial processes or for electricity generation. The potential for analogous initiatives in other industrial plants is very high as illustrated in a study (Stricker 2006) which analysed manufacturing processes within the eight largest Canadian manufacturing sectors accounting for approximately $2 / 3$ of the total energy used by Canadian industries. This analysis shows that approximately
$70 \%$ of the input energy is released to the environment via the following four waste heat streams:

- Liquid streams (at between 50 and $300{ }^{\circ} \mathrm{C}$ ) carry approximately $550 \mathrm{PJ} /$ year,

- Stack losses (at between 150 and $800{ }^{\circ} \mathrm{C}$ ) carry approximately $550 \mathrm{PJ} /$ year,

- Low to medium steam losses (at between 100 and $250^{\circ} \mathrm{C}$ ) carry approximately $310 \mathrm{PJ} / \mathrm{year}$,

- Process gases and vapours (at between 80 and $500{ }^{\circ} \mathrm{C}$ ) carry approximately $290 \mathrm{PJ} /$ year.

The potential for greenhouse gas (GHG) reduction associated with waste heat recovery is also large. Thus, the theoretical GHG reduction that can be attained by recovering the above mentioned waste heat from the eight largest Canadian manufacturing sectors is 2.5 times the target of $45 \mathrm{Mt}$ of GHG suggested by the Kyoto protocols.

In this article we present and analyse three methods which can be used to convert low $\left(80\right.$ to $\left.150^{\circ} \mathrm{C}\right)$ or intermediate (up to $350{ }^{\circ} \mathrm{C}$ ) temperature thermal energy into mechanical work and electricity. They can be associated with renewable thermal sources (such as geothermal or solar energy) or with industrial waste heat and are based on thermodynamic cycles using organic fluids, mixtures or fluids with very low critical temperatures. In each case we present a brief description of some prototypes or industrial installations, a review of the pertinent literature as well as parametric energy, exergy and thermo-economic (based on finite size thermodynamics) analyses.

\section{PRototypes, Industrial SyStems \& ANALYTICAL STUDIES}

The working fluid for systems with low or intermediate temperature sources must satisfy several safety, environmental, performance and economic criteria. 
Among the safety aspects, flammability and auto ignition are particularly important. The latter is a problem for longer alkanes at temperatures exceeding $200{ }^{\circ} \mathrm{C}$. Information on the degree of flammability and the auto ignition temperature can be obtained from the suppliers of these fluids. Environmental criteria include the ozone depletion potential (ODP), the global warming potential (GWP) and the atmospheric lifetime (ALT). For many of the working fluids under consideration these properties have been published by the US Environmental Protection Agency (2006).

From a thermodynamic point of view, the potential working fluids are classified in categories depending on the slope of the saturated vapour line on the temperature-entropy diagram. Thus, dry fluids have positive slopes (the saturated vapour line in the T-s diagram is overhanging) while wet fluids have negative slopes (the saturated vapour line is bell shaped).

The use of water for such applications must be considered carefully, in particular for medium temperature sources, because of the existing expertise and technology. For low temperature sources the advantage of organic fluids over water is considerable based on the volume ratio at the turbine outlet and inlet. This can be smaller by an order of magnitude for organic fluids than for water and hence allows the use of simpler and cheaper turbines (Rogers \& Mayhew 1992). An experimental and numerical study conducted by Yamamoto et al. (2001) shows the advantages of organic fluids over water for low temperature heat sources. Similar comparisons between water and the binary mixture of ammonia-water are presented in a subsequent section of the present paper.

\subsection{Rankine Cycle Systems Using Organic Fluids (ORC)}

Organic Rankine cycle engines are not new. In large power plants, they're currently used to convert energy from lowgrade, second-stage steam heat. And some very large solarthermal power plants rely on ORCs, including the recently completed Nevada One, capable of generating $64 \mathrm{MW}$ of power (enough for 40,000 homes). They have also been used to produce electricity from other medium or low temperature sources such as geothermal steam or brine.

A recent study by Prabhu (2006) analysed the optimization and economics of solar trough ORC electricity systems (STORES, Fig. 1). Contrary to the prevailing wisdom, this study is based on the postulate that small STORES offer more advantages than large ones or those coupled with fossil fuel plants. It argues that small STORES can be built quickly and should aim to provide local retail demand, because local value and prices are often higher. Since steam technology is no longer available in small sizes and not appropriate for low to medium temperature sources it opted for ORC engines which have been used in geothermal power plants for a long time. The study considered different heat transport and working fluids as well as several thermodynamic cycles. It concluded that a technically optimised STORES plant consists of a two tier cascade system, with toluene as the high temperature working fluid and butane as the low temperature one. The heat transport fluid is Therminol VP-1. It was recommended that the plant should include storage for continuous electricity generation. The author suggests that such plants with 1-10 MW capacity would be economically attractive for isolated communities in Africa and the Middle East. Grid-connected customers in the US with large loads concerned about reliability and paying high prices for peak electricity are also potential customers for STORES. The concept was adopted by a US electric utility in order to meet renewable energy requirements. ORC power plants using geothermal energy have been built and are in operation in different parts of the world. DiPippo (2004) describes two $1 \mathrm{MWe}$ prototypes built in Japan.

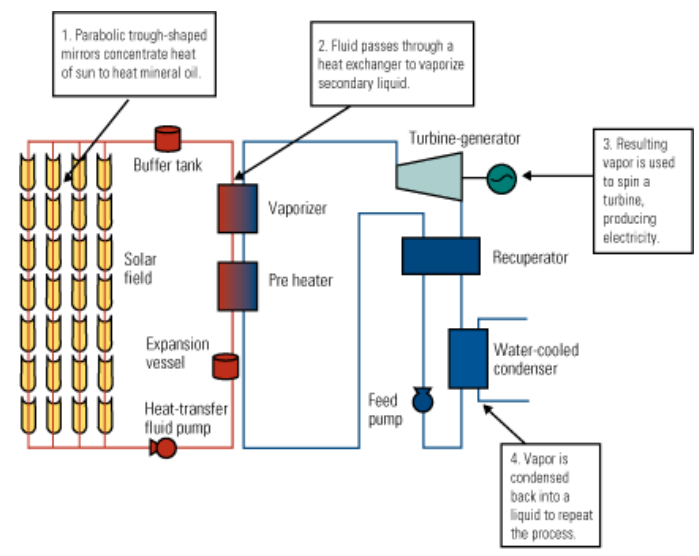

Fig. 1. Schematic representation of the Arizona solar trough organic Rankine energy system

The first one used isobutane as the working fluid and the heat source was a combination of steam and brine at $130{ }^{\circ} \mathrm{C}$ (Fig. 2). The second prototype used R-114 $\left(\mathrm{C}_{2} \mathrm{Cl}_{2} \mathrm{~F}_{4}\right)$ and the heat source was brine at $140{ }^{\circ} \mathrm{C}$. Calculated first and second law efficiencies are $12.9 \%$ and $53.9 \%$ respectively for the first prototype and $9.8 \%$ and $21.6 \%$ respectively for the second one.

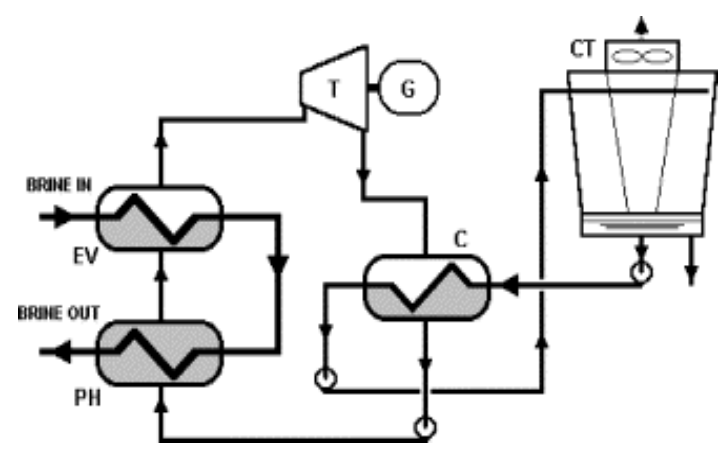

Fig. 2. Nigorikawa geothermal ORC plant (brine temperatures: inlet $140{ }^{\circ} \mathrm{C}$, outlet $92^{\circ} \mathrm{C}$; brine flow rate 50 $\mathrm{kg} / \mathrm{s}$ ) (DiPippo 2004)

The power plant in Altheim (Fig. 3), a small town in Austria, uses geothermal water to generate electricity and to supply a district heating system (Pernecker \& Uhlig 2002). The thermal power input from geothermal water at an inlet temperature of $106^{\circ} \mathrm{C}$ and a flow rate of $86 \mathrm{l} / \mathrm{s}$ is 12.4 MWth while the cooling water flow rate and inlet temperature are respectively $340 \mathrm{l} / \mathrm{s}$ and $10{ }^{\circ} \mathrm{C}$. The net electric output is $1000 \mathrm{kWe}$. According to Saleh et al. (2007) this power plant "...initially used nperfluoropentane (which) is environmentally not very friendly (and) has a relatively low thermal efficiency".

Following these observations, Saleh et al. (2007) 
performed a thermodynamic analysis of 31 pure working fluids for ORC cycles operating between 100 and $30{ }^{\circ} \mathrm{C}$. They considered three cycles for wet fluids (with saturated vapour at the turbine inlet and superheated or saturated conditions at its outlet as well as one with superheated vapour at both the inlet and outlet of the turbine), two cycles for dry fluids (with saturated or superheated vapour at the turbine inlet) and two more cycles with heat addition at supercritical pressures (with saturated or superheated conditions at the turbine outlet). They found that the highest thermal efficiencies are obtained with dry fluids in subcritical cycles with regenerator (thus, for n-butane the calculated efficiency was $13 \%$ ). They also performed a pinch analysis for the heat transfer between the heat source at $120^{\circ} \mathrm{C}$ and the working fluid and reported that the largest amount of heat can be transferred to a supercritical fluid and the least to a high-boiling subcritical fluid.

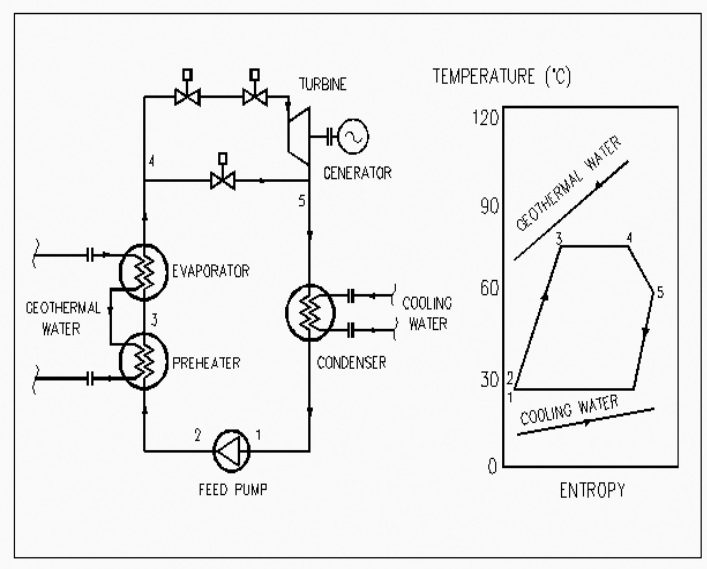

Fig. 3. Schematic representation and thermodynamic cycle of the Altheim geothermal plant (Pernecker \& Uhlig 2002)

Another power plant which generates electricity with an ORC and supplies district heating is described by Obernberger et al. (2002). When completed, this biomassfuelled system was expected to provide about 60000 $\mathrm{MWh} /$ year of district heat and $7200 \mathrm{MWh} /$ year of electricity. Economic evaluations based on the data collected from this project show that such a plant based on a $1000 \mathrm{kWe}$ ORC system can achieve specific electricity production costs between 0.09 and $0.14 \mathrm{eur} / \mathrm{kWe}$ depending on the fuel price. These costs enable an economically viable application of this technology in European countries which provide funding for electricity production from renewable energy sources.

A prototype of a small hybrid power plant integrating two superposed ORCs which convert into electricity the thermal energy provided by a field of sun tracking flat solar concentrators was constructed by Kane et al. (2003). Waste heat from both the exhaust gases and the cooling liquid of a Diesel engine was also used as a heat source (Fig. 4). Hermetic scroll expanders were used in both ORCs. The working fluid in the high temperature ORC is HCFC123 and its nominal power is $5 \mathrm{kWe}$. The heat rejected by the condenser of this unit evaporates the working fluid of the low temperature ORC (HFC134a) whose nominal power is $8 \mathrm{kWe}$. Laboratory tests of the two ORCs using heated oil at a temperature of 130 to $165{ }^{\circ} \mathrm{C}$ to supply heat to the high temperature unit and water at $7{ }^{\circ} \mathrm{C}$ to condense the working fluid of the low temperature ORC resulted in net efficiencies of up to $12 \%$. The electrical output varied almost linearly between 3 and $10 \mathrm{kWe}$ with the supply heat rate. This performance was considered satisfactory since for these conditions the Carnot efficiency is approximately $30 \%$. In situ tests have also been made with the integration of the Diesel engine and the solar collectors during approximately 110 hours. The source and sink temperatures varied between $120-150$ and $7-9{ }^{\circ} \mathrm{C}$ respectively while the power range varied between 11 and $13 \mathrm{kWe}$. The electricity produced by the hybrid plant was $500 \mathrm{kWh}$. The authors concluded that the hybrid power plant has "adequate operational characteristics with good performances over a broad range of conditions".

An overview of products and systems available from commercial sources was compiled by Duffy (2005).

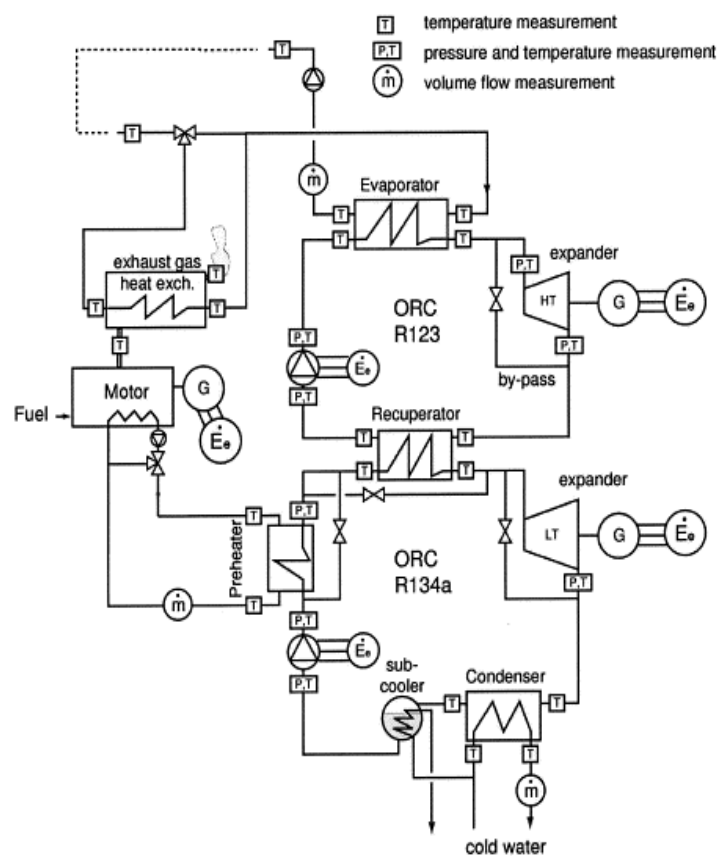

Fig. 4. Schematic representation of the dual source ORC plant (Kane et al. 2003)

\subsection{Systems with Supercritical Heat Addition to the Working Fluid}

It is important to distinguish between supercritical and trans-critical power plants. The former is essentially a Brayton cycle using a single phase fluid such as air or combustion gases. The clear odorless, nontoxic refrigerant C318 as well as propane and hexane are other fluids under consideration for supercritical nuclear power plants (Wright 2007). On the other hand, in a trans-critical plant heat rejection takes place at sub-critical pressures and the working fluid changes into liquid during this operation. The liquid is then pumped to a pressure exceeding its critical value and heat addition takes place at this supercritical pressure.

More than 400 trans-critical steam power plants are operating in the US, in Europe, Russia and in Japan. The most modern such plants have efficiencies above $45 \%$ (LHV). Besides the obvious economic advantages of such high efficiency values, environmental impacts are also reduced. Indeed, a one percent increase in efficiency 
reduces specific emissions such as $\mathrm{CO}_{2}, \mathrm{NO}_{\mathrm{x}}, \mathrm{SO}_{\mathrm{x}}$ and particulates by two percent. However such steam power plants operate with turbine inlet temperatures close to $600{ }^{\circ} \mathrm{C}$ and are not suited for the applications envisaged here. For low temperature heat sources other working fluids must thus be considered.

Trans-critical systems with fluids other than water are not technologically as developed as the ones based on ORC. Nevertheless they offer an important thermodynamic advantage which becomes evident by analysing the heat transfer process between the heat source stream (brine or steam of a geothermal plant, solar collector fluid, flue gases of internal combustion engine, etc) and the working fluid of the power plant (Figs. 1, 2, 3 and 4). The heat source stream flowing through the evaporator is cooled down as illustrated by line (1) in Fig. 5. This situation is quite different from the one prevailing in traditional (fossil fuelled or nuclear) subcritical power plants in which the temperature of the heat source is maintained essentially constant by the continuous burning of fuel. In the case of ORC systems the working fluid is evaporated at a constant subcritical pressure as illustrated by line (3) in Fig. 5. Therefore its average temperature during this process is considerably lower than that of the heat source and the heat transfer process produces an important exergy destruction (its irreversibility is very large). On the other hand, if the working fluid pressure is higher than its critical value the corresponding temperature increases during the heat transfer process as illustrated by line (2) in Fig. 5. Therefore the irreversibility and exergy destruction are considerably lower in this case and the energy transferred to the working fluid is higher.

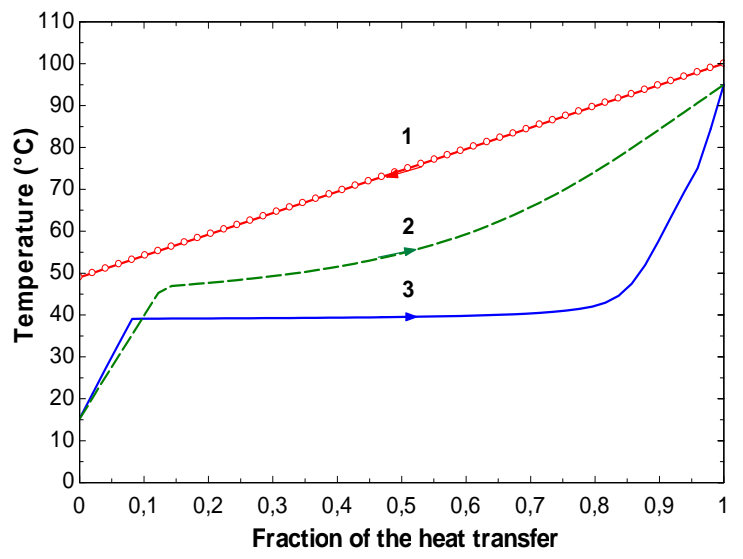

Fig. 5. Typical temperature variations for sub-critical and supercritical heat addition

In view of this situation some studies examining the potential of working fluids other than water for supercritical or trans-critical low temperature power cycles have been published. They consider inorganic gases, halocarbons and hydrocarbons. Thus, Gu and Sato (2002) analysed supercritical cycles using propane, R-125 and R-134a as the working fluid for a particular geothermal resource (saturated liquid brine at $229.4^{\circ} \mathrm{C}, 2763 \mathrm{kPa}$ with a mass flow rate of $230.2 \mathrm{~kg} / \mathrm{s}$ ). The two HFC refrigerants have no ozone depletion potential and are non-flammable unlike propane. Their thermodynamic analysis indicates that, for this particular case, propane produces the highest power output and that R-134a has the best first and second law efficiencies.
Considerable interest is manifested recently in the literature for both supercritical and trans-critical cycles using $\mathrm{CO}_{2}$ as the working fluid. This interest in $\mathrm{CO}_{2}$, whose critical temperature and pressure are respectively $31.1^{\circ} \mathrm{C}$ and $7.38 \mathrm{MPa}$, extends to areas other than electricity generation (Sawalha 2005) and is due to the following reasons:

- it is not toxic and not inflammable,

- it is abundant, affordable, inert and does not require recycling,

- it is compatible with standard construction materials and lubricants,

- its density is high and thus the dimensions of the cycle components are small.

On the other hand it may cause suffocation in case of an accident and necessitates strong walls since the operation pressures are generally high.

Supercritical $\mathrm{CO}_{2}$ plants are under consideration for advanced nuclear reactors. In such cases, typical conditions of the $\mathrm{CO}_{2}$ at the turbine inlet would be 200 bars, $650{ }^{\circ} \mathrm{C}$ leading to thermal efficiencies of approximately 45\% (Dostal 2004; Kato et al. 2004). On the other hand, trans-critical $\mathrm{CO}_{2}$ cycles are under consideration for lower temperature heat sources. Thus, Zhang et al. (2007) analysed a solar powered $\mathrm{CO}_{2}$ transcritical plant (Fig. 6) intended for commercial or institutional buildings requiring $0.3-10 \mathrm{~kW}$ of electricity and $1-50 \mathrm{~kW}$ of heat. Evacuated solar collectors are used to heat the $\mathrm{CO}_{2}$ and measured values of the power generation efficiency and the heat output efficiency for typical summer conditions in Osaka, Japan are 0.25 and 0.65 respectively. They also developed a numerical model of the system which was validated with experimental data and was used to perform parametric studies.

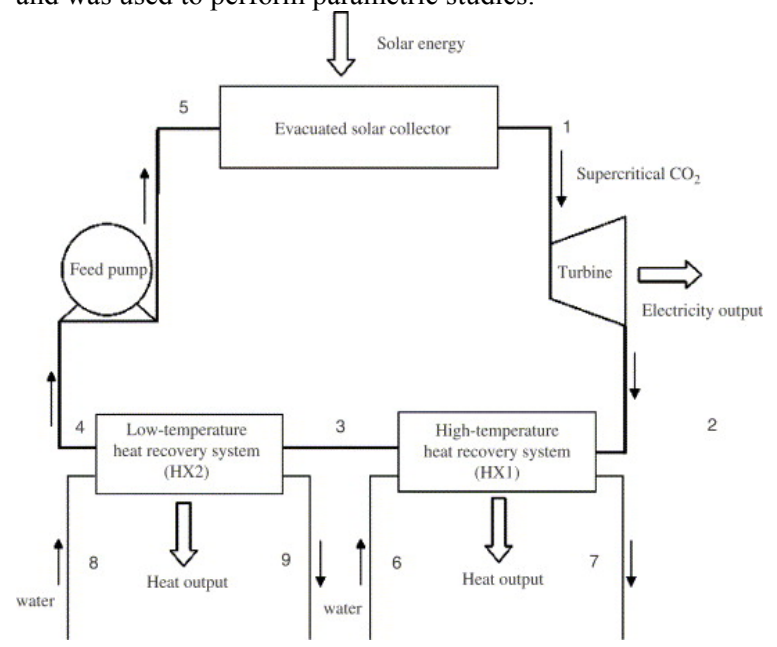

Fig. 6. Solar powered trans-critical $\mathrm{CO}_{2}$ cycle for electricity generation and heating (Zhang et al. 2007)

They thus established that the electric power output increases with solar radiation, air temperature, collector area and water inlet temperature but decreases with increasing heat exchanger area. Chen et al. (2006) compared an ORC cycle using $\mathrm{R} 123$ and a $\mathrm{CO}_{2}$ transcritical cycle powered by exhaust gases at $150{ }^{\circ} \mathrm{C}$ from an internal combustion engine. Identical mass flow rates for the heat source $(0.4 \mathrm{~kg} / \mathrm{s})$, mean heat rejection conditions 
as well as isentropic efficiencies for the pump and expander were assumed. The numerically calculated results show that under these conditions the carbon dioxide trans-critical cycle has a slightly higher power output, is more compact and more environmentally friendly than the ORC.

Yamaguchi et al. (2006) constructed a prototype of the trans-critical $\mathrm{CO}_{2}$ power plant (Fig. 6) analyzed by Zhang et al. (2007). However, since no turbine for supercritical $\mathrm{CO}_{2}$ was available a throttling valve was used in its place. Therefore no electricity was produced and the thermodynamic state at the throttling valve outlet was different from the one at the turbine outlet. Nevertheless, the authors concluded that the trans-critical operation of the system was stable. They estimated the average electricity and thermal outputs at approximately $400 \mathrm{~W}$ and $1050 \mathrm{~W}$ respectively. Typical conditions at the solar collector outlet were $165{ }^{\circ} \mathrm{C}$ and $8.7 \mathrm{MPa}$ for a flow rate of $6.7 \mathrm{~g} / \mathrm{s}$. They also estimated that a power plant 10 times larger than this prototype would replace $8500 \mathrm{~m}^{3} /$ year of oil and reduce greenhouse gas emissions by $28200 \mathrm{~kg} /$ year.

Despite such results which indicate that the $\mathrm{CO}_{2}$ transcritical cycle, due to the efficient temperature matching between the heat source and the working fluid, has considerable potential as a means for converting low grade heat into electricity it has not received as much attention as the ORC cycle.

\subsection{Systems Using Mixtures as Working Fluid}

The temperature of these fluids increases during heat addition as illustrated by line (2) in Fig. 5. Figure 7 illustrates this phenomenon for a binary mixture of water and ammonia. For an ammonia mass fraction equal to 0.7 and a pressure of $2.5 \mathrm{MPa}$ the temperature of the mixture increases from $76{ }^{\circ} \mathrm{C}$ at $\mathrm{A}$ (saturated liquid condition) to $170^{\circ} \mathrm{C}$ at $\mathrm{B}$ (saturated vapor condition). The resulting good temperature matching between the two streams in the vapor generator reduces entropy generation (i.e., irreversibility) with respect to that in an ORC system.

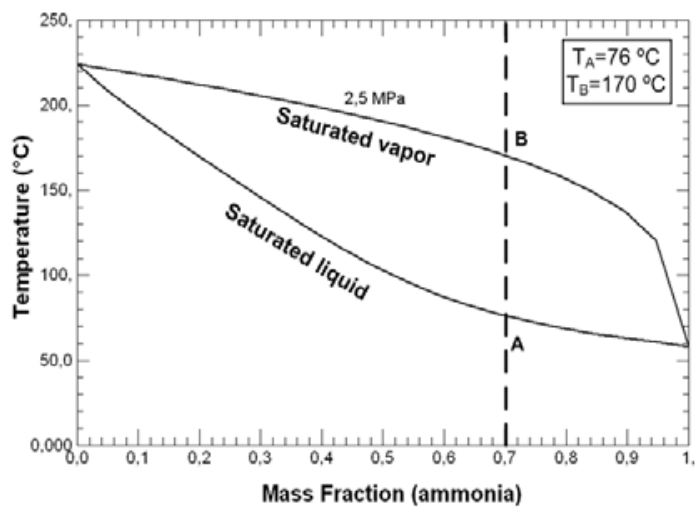

Fig. 7. Temperature increase during constant pressure evaporation of an ammonia-water mixture

The first such power cycle using an ammonia-water mixture was proposed by Maloney \& Robertson (1953). Figure 8 shows a schematic representation of their system. Saturated vapor rich in ammonia (state 6) is superheated to state 7 and expanded through the turbine to state 8 while saturated liquid weak in ammonia (state 9) is cooled in the recuperator to state 10 and throttled to state 11 . The two streams from 8 and 11 are mixed and cooled down to state 1. This basic solution is then pumped to a high pressure (state 2), heated in the recuperator to state 4 and evaporated to state 5 . Work on this concept was abandoned for approximately 25 years because the results of Maloney \& Robertson (1953) did not show any significant advantage of their cycle over the Rankine cycle.

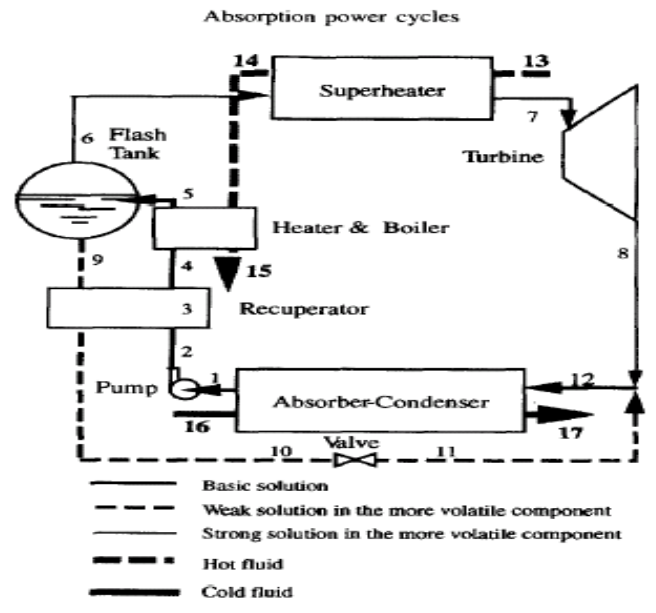

Fig. 8. Schematic representation of the Maloney \& Robertson cycle using an ammonia-water mixture

However, Kalina (1983) proposed another cycle using an ammonia-water mixture and showed that its thermal efficiency is $30-60 \%$ higher than comparable steam power plans. El Sayed \& Tribus compared the Rankine and Kalina cycles for identical thermal boundary conditions and concluded that the latter can have $10-30 \%$ higher thermal efficiencies. Later publications by Kalina and his coworkers (Kalina \& Leibowitz 1989, Kalina 1991, Kalina et al. 1991) explained the basic advantages of this technology which has been patented and is now commercialized by a company headed by Kalina. Ibrahim \& Klein (1996) performed a thermodynamic analysis of the Maloney \& Robertson and the Kalina cycles operating with low temperature heat sources. They showed that, for a fixed ratio of the thermal-capacitance-rates of the sink to source streams, the Kalina cycle produces more power when the evaporators are large. On the other hand, for small evaporators the Maloney \& Robertson cycle produces more power.

There exist several different configurations of the Kalina cycle depending essentially on the heat source temperature. Figure 9 shows a simplified diagram of the configuration used in geothermal power plants. The ammonia-water mixture is evaporated in the heat exchanger. The saturated, rich in ammonia vapor enters the turbine while the saturated, weak in ammonia liquid is cooled in the recuperator, throttled and mixed with the low pressure mixture from the turbine outlet. The resulting basic mixture is cooled in a second recuperator, condensed, pumped to a high pressure, heated in the two recuperators and returned to the main heat exchanger. The temperatures, pressures and mass flow rates in Fig. 9 give the operating conditions of the geothermal power plant operating in Husavic, Iceland (Hjartarson et al. 2005). It entered service in July 2000 and is the fourth operational Kalina cycle power plant but its first geothermal 
application. This plant was designed to produce $2000 \mathrm{~kW}$ with a brine flow of $90 \mathrm{~kg} / \mathrm{s}$ at $124^{\circ} \mathrm{C}$. The ammonia mass fractions for the rich, basic and weak mixtures are 0.95 , 0.82 and 0.50 respectively. The cooled brine emerging from the main heat exchanger and the cooling water from the plant condenser are both used to supply the community's district heating system as well as some commercial activities. In its initial phase the plant encountered some difficulties in achieving the design output due to a faulty component and a brine temperature of $121{ }^{\circ} \mathrm{C}$, i.e. slightly lower than the design value. After replacement of the faulty component, a performance test conducted in 2001 showed that the net output of the plant, corrected for the new brine temperature, was $95 \%$ of the design value. Later, an inspection showed evidence of corrosion of the turbine blades which were made from $13 \% \mathrm{Cr}$ steel. They have been replaced by titanium and it is now expected that this power plant will become a convincing example of efficient multi-use of geothermal energy. On this point, it is important to note that $29 \%$ of the total energy from the geothermal field is sold for different uses (including the generation of electricity) while an additional $39 \%$ is utilized by heating a bathing lagoon for recreational purposes.

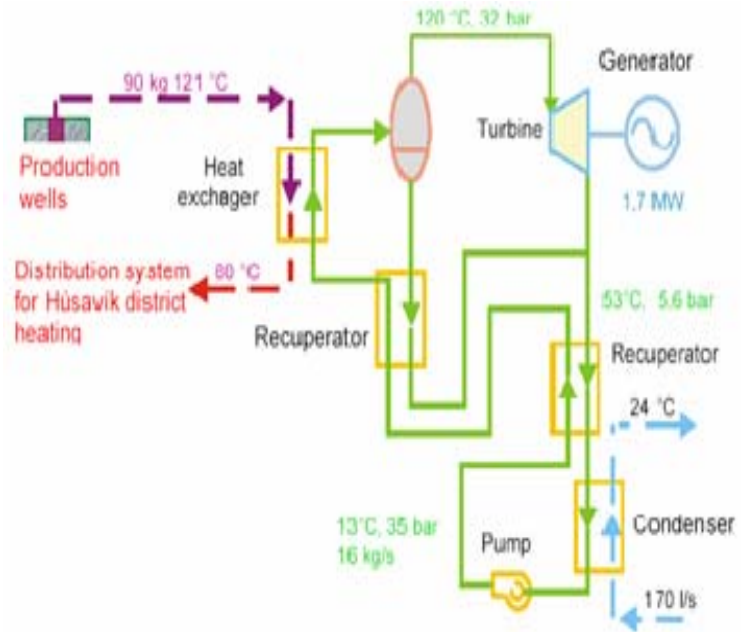

Fig. 9. Schematic representation of the Kalina cycle geothermal power plant in Husavik, Iceland

Another cycle using an ammonia-water mixture as the working fluid was proposed by Goswami (1995). It is a combination of the Rankine power cycle and the absorption refrigeration cycle as shown in Fig. 10. The basic mixture is partially evaporated at high pressure in the boiler. The fairly rich vapor (state 4) is further enriched in the condenser/rectifier by partial condensation. The weak in ammonia liquid (state 5) is returned to the boiler while the almost pure ammonia vapor (state 6) is superheated and expanded in the turbine. The temperature of the fluid at state 8 is lower than the ambient; therefore it can provide refrigeration in the cooler. It is then absorbed by the throttled weak solution (state 12) to regenerate the basic mixture (state 1). This is then pumped to the high pressure (state 2), preheated to state 3 and returned to the boiler. The high pressure side of this cycle is essentially the same as in the Kalina cycle (cf. Fig. 9) while the low pressure side is essentially similar to the absorption refrigeration cycle (the evaporator of the latter is replaced by the cooler of Fig. 10). Therefore, the Goswami cycle combines the reduction of irreversibilities in the boiler associated to the use of a binary mixture with the reduction of the effective sink temperature due to a very low temperature at state 8 . Simulations of the cycle (Goswami \& Xu 1999) for source temperatures in the range of flat plate and low concentration solar collectors show that it has a very high efficiency: thus, for $400 \mathrm{~K}$ in the boiler, $410 \mathrm{~K}$ at the turbine inlet and an ambient temperature of $280 \mathrm{~K}$ the calculated first law efficiency is $23.5 \%$ while the corresponding Carnot efficiency is $31.7 \%$. An experimental system without the turbine was constructed and its performance was monitored (Tamm \& Goswami 2003). These results showed that the vapor generation and absorption condensation processes exhibit expected trends but with deviations from ideal and equilibrium models. The potential for combined turbine work and cooling output was confirmed by the experimental setup.

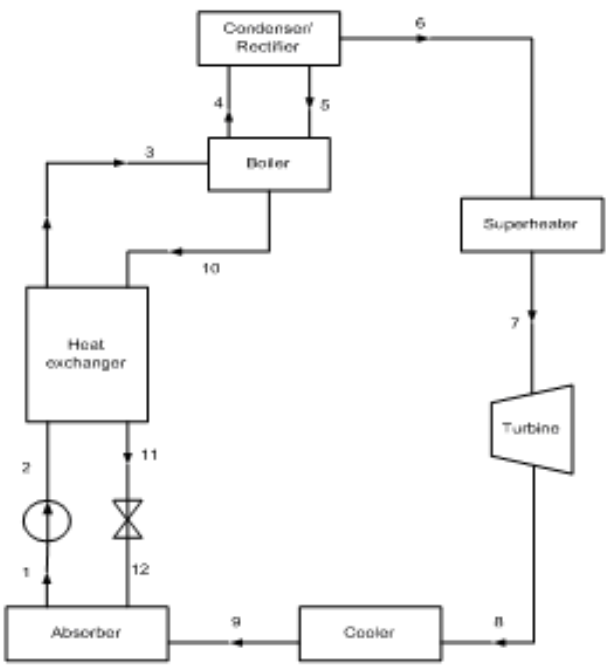

Fig. 10. Schematic representation of the Goswami power/refrigeration cycle.

\section{THERMODYNAMIC MODEL}

Figure 11 shows the schematic diagram of a generic system (ORC, trans-critical cycle or system using a mixture of fluids) used to recover energy from a lowtemperature gas stream whose mass flow rate $m_{\text {source }}$ and temperature $T_{\text {source, in }}$ are known. It is similar to the Rankine and Brayton cycles: the working fluid receives heat at a relatively high pressure, expands in a turbine and rejects heat at a low pressure in the condenser towards water from a lake or river whose temperature $T_{\text {sink,in }}$ is specified. The condensate is compressed and preheated in the regenerator if the temperatures at states 2 and 5 permit it.

\subsection{Energy (1st law) analysis}

The objective of energy analysis is to calculate the thermal efficiency $\eta_{\text {therm }}$ and specific net work $w_{\text {net }}$ of the system for different operating conditions. The equations used to model the performance of the system express mass and energy balances. They are simplified using the following assumptions:

- Each component is considered as an open system in steady-state operation.

- The kinetic and potential energies as well as the heat and friction losses are neglected.

The expressions for the isentropic efficiencies of the pump and turbine are also used in the analysis. 
For the calculations presented here the temperatures of the working fluid at states 1 and 4 are respectively set equal to $\left(\mathrm{T}_{\text {sourse,in }}-\Delta \mathrm{T}\right)$ and $\left(\mathrm{T}_{\text {sink,in }}+\Delta \mathrm{T}\right)$ where $\Delta \mathrm{T}$ is a fixed design parameter. The efficiencies of the turbine and the pump are also fixed. The regenerator is modeled either by fixing its effectiveness or by fixing the temperature change of the warm stream.

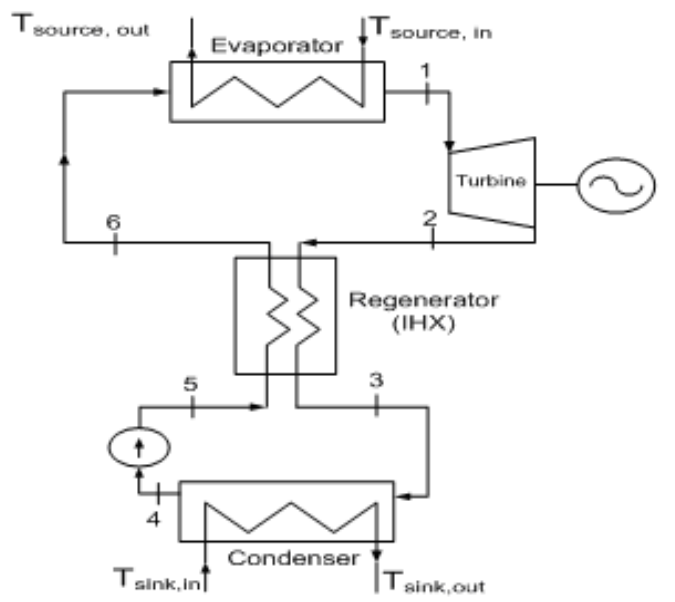

Fig. 11. Generic system used in thermodynamic calculations

\subsection{Exergy (2nd law) analysis}

The objective of exergy analysis is to determine the operating conditions of the system which destroy the least available work. With the previously stated assumptions, the exergy of the working fluid at each state and the exergy destruction for each component are obtained from expressions found in thermodynamic textbooks. The evaluation of these quantities in the evaporator and the condenser requires the outlet states of the source and the sink. For this purpose the mass flow rates of the working fluid and of the cooling water must be specified. This is achieved by assuming that the gaseous heat source is air and by fixing the value of the ratio $\alpha$ between the net power generated by the system of Fig. 11 to the maximum power output corresponding to the specified characteristics of the source and sink. The latter is produced by a Carnot engine operating between $\mathrm{T}_{\text {source, in }}$ and $\mathrm{T}_{\text {sink, in }}$ :

$$
\mathrm{W}_{\max }=\dot{\mathrm{m}}_{\text {source }} \mathrm{C}_{\mathrm{p} \text {, source }}\left(\mathrm{T}_{\text {source }}-\mathrm{T}_{\text {sink }}\right)\left(1-\mathrm{T}_{\text {sink }} / \mathrm{T}_{\text {source }}\right)
$$

Therefore, the working fluid mass flow rate is

$$
\mathrm{m}_{\mathrm{f}}=\left(\alpha \mathrm{W}_{\max }\right) / \mathrm{w}_{\text {net }}
$$

The mass flow rate of the cooling water is calculated from the energy balance for this component by fixing the corresponding temperature increase.

The total exergy destruction $\mathrm{E}_{\mathrm{d} \text {,total }}$, i.e. the summation of the exergy destruction by all its components, is used to calculate the $2^{\text {nd }}$ law, or exergetic, efficiency of the system from the following equation:

$\eta_{\mathrm{ex}}=1-\mathrm{E}_{\mathrm{d}, \mathrm{total}} / \mathrm{E}_{\mathrm{source}, \text { in }}$

\subsection{Finite Size Thermodynamics Analysis}

The objective of this type of analysis is to calculate the size of the heat exchangers in the system of Fig. 11 or, minimally, the value of UA, the product of their area and overall thermal conductance. For this purpose, the heat transferred between the fluids in each of the three heat exchangers shown in Fig. 11 is expressed in terms of either the logarithmic mean temperature or the heat exchanger effectiveness (Incropera \& Dewitt 2002).

\section{RESUlTS OF THE THERMODYNAMIC ANALYSIS}

The results presented here were calculated for different values of $T_{\text {source,in }}$ and fixed values of $m_{\text {source }}(314.5 \mathrm{~kg} / \mathrm{s})$, $\Delta \mathrm{T}\left(5^{\circ} \mathrm{C}\right)$ as well as $\eta_{\text {pump }}=\eta_{\text {turbine }}=0.8$. It is also assumed that at the entrance of the pump (state 4 in Fig. 11) the fluid is saturated liquid. Under these assumptions the condenser pressure is constant, its value being the saturation pressure at $15{ }^{\circ} \mathrm{C}$. The properties of the gaseous heat source are those of air while the cooling fluid in the condenser is water. Other parameters specific to each of the three systems under consideration are specified in the corresponding section. The thermodynamic properties of the working fluids and all other results were calculated with Engineering Equation Solver (Klein 2007).

\subsection{Organic Rankine Cycle (ORC)}

Four fluids were studied, namely R123, R141b, n-pentane and n-butane. They were chosen because the risk of condensation at the turbine outlet is for each of them small due to the shape of the corresponding saturated vapour line on the T-s diagram. The performance of the regenerator was defined by setting the temperature difference $\left(T_{2}-T_{3}\right)$ equal to one of the following three values: 0,10 or $20^{\circ} \mathrm{C}$.

Figure 12 shows typical results for a system using R123, a heat source temperature of $200{ }^{\circ} \mathrm{C}$ and operating with different values of the maximum pressure $\left(\mathrm{p}_{1}=\mathrm{p}_{6}=\mathrm{p}_{5}\right)$. The range of admissible values for this pressure is from a minimum slightly greater than the condenser pressure (for which $\mathrm{w}_{\text {net }}=0$ ) and a maximum value equal to the saturation pressure for $T_{1}$. The specific net power output is negligible for small values of this pressure, increases rapidly to a maximum value and then decreases. The value of $\mathrm{w}_{\text {net }}$ does not depend on the effectiveness of the regenerator. On the other hand, the thermal efficiency of the cycle, which increases monotonically with the evaporator pressure, also increases as the performance of the regenerator improves. However, even the highest calculated value remains well below the Carnot efficiency corresponding to these operating conditions which is approximately $38.5 \%$. It is obvious from these results that the maximum values of $\mathrm{w}_{\text {net }}$ and $\eta_{\text {therm }}$ do not correspond to the same evaporator pressure. Analogous results are obtained for the other two fluids and other source temperatures.

The best value of $\mathrm{w}_{\text {net }}$ is produced by n-pentane which also operates at the lowest evaporator pressure. It should be noted that for every one of these fluids the values of $\mathrm{w}_{\text {net }}$ and the corresponding $\mathrm{p}_{\mathrm{ev}}$ increase with $\mathrm{T}_{\text {source,in }}$. Furthermore, for every one of these fluids the values of 
$\eta_{\text {therm }}$ and the corresponding $p_{\mathrm{ev}}$ increase with $\mathrm{T}_{\text {source,in. }}$. It is interesting to note that in the case of n-butane the maximum values of $\mathrm{w}_{\text {net }}$ and $\eta_{\text {therm }}$ correspond to the same evaporator pressure. The best value of $\eta_{\text {therm }}$ is obtained in the case of $\mathrm{R} 141 \mathrm{~b}$ with an evaporator pressure slightly higher than the one for n-pentane. However, based on these results alone, it is not possible to make a definite recommendation on the choice between these four fluids.
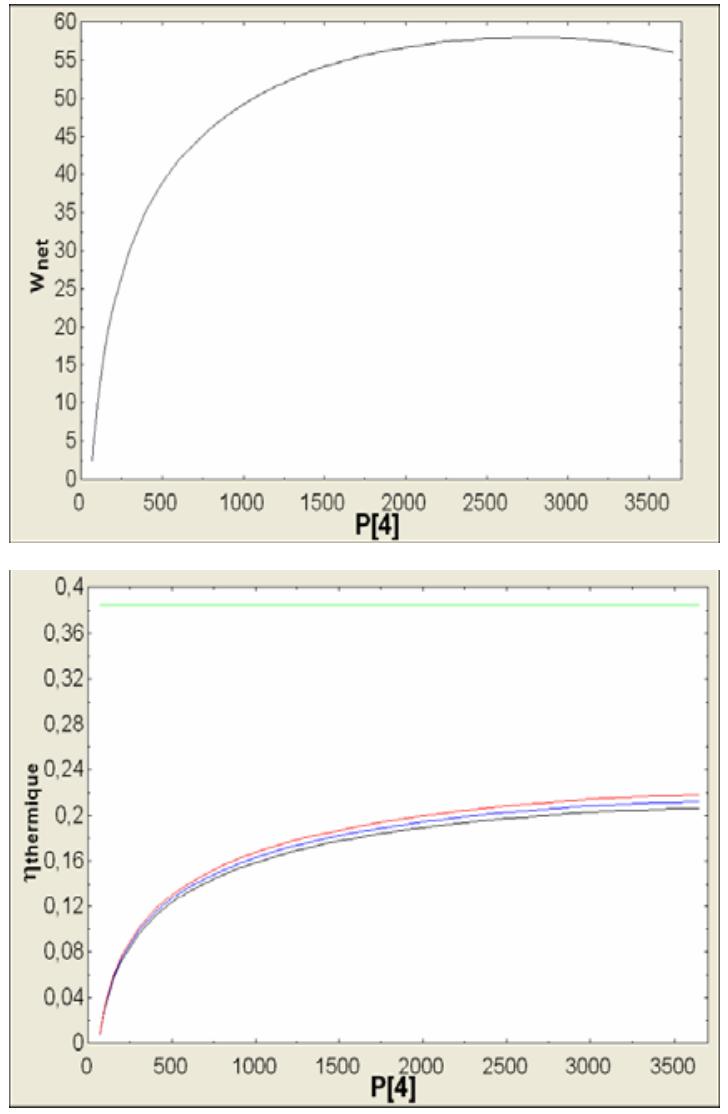

Fig. 12. Specific net power output $(\mathrm{kJ} / \mathrm{kg})$ and thermal efficiency for an ORC with R123 for different evaporation pressures $(\mathrm{kPa})$ (heat source temp $=200{ }^{\circ} \mathrm{C}$, heat sink temp $=10^{\circ} \mathrm{C}$ )

In the present case the second law analysis was limited to the evaluation of the pinch in the evaporator. This value should obviously not be negative. Since $T_{1}$ is always less than $T_{\text {source,in }}$ the critical temperature difference between the heat source and the working fluid occurs when the latter is saturated liquid (see Fig. 5). Some typical results of this analysis are presented in Fig. 13 for a system using R141b, a heat source temperature of $200{ }^{\circ} \mathrm{C}$ and different values for $\mathrm{p}_{\mathrm{ev}}$ and for the ratio $\alpha$ between the net power generated by the system of Fig. 11 to the maximum power output calculated according to Eq. 14. The vertical axis in this figure indicates temperatures in ${ }^{\circ} \mathrm{C}$. The horizontal lines indicate the saturation temperature for the pressure specified next to each of these lines. This is the temperature of the saturated liquid at the beginning of evaporation (cf. line 3 in Fig. 5). The corresponding temperature of the heat source can be calculated for any given combination of $\mathrm{p}_{\mathrm{ev}}$ and $\alpha$ by applying the expression of energy conservation to a control volume which includes the evaporation and superheating processes. For a fixed value of $p_{\mathrm{ev}}$, this temperature of the heat source decreases linearly with increasing mass flow rate of the working fluid which in turn is proportional to $\alpha$ (cf. Eq. 15). The value of this temperature is represented by the inclined straight line in Fig. 13. Since it must be higher than, or in the limit equal to, the saturation temperature of the working fluid the intersection of the horizontal and inclined lines determines the greatest possible value of $\alpha$ for each evaporation pressure. Based on the results of Fig. 13 we note that, as $p_{\mathrm{ev}}$ increases, this greatest value of $\alpha$ initially increases, reaches a maximum and then decreases. Similar results have been obtained for all values of $\mathrm{T}_{\text {source,in }}$ and each of the four fluids under consideration.

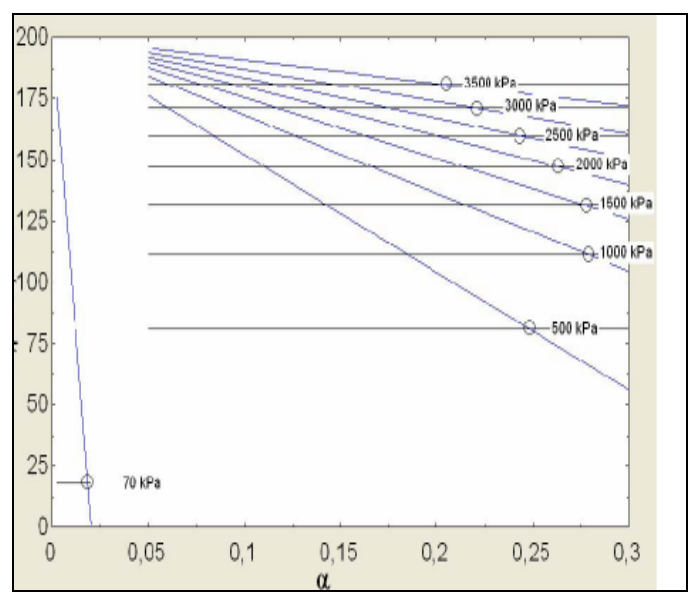

Fig. 13. Corresponding temperatures $\left(\right.$ in $\left.{ }^{\circ} \mathrm{C}\right)$ of saturated liquid R141b and gaseous heat source

For $\mathrm{T}_{\text {source, in }}=200{ }^{\circ} \mathrm{C}$, n-butane produces the highest net power but requires by far the highest evaporation pressure. Both $\alpha$ and the corresponding values of $p_{\mathrm{ev}}$ increase when $\mathrm{T}_{\text {source, in }}$ increases. For source temperatures lower than 200 ${ }^{\circ} \mathrm{C}, \mathrm{R} 141 \mathrm{~b}$ produces more power and requires the lowest evaporation pressure.

Finally, the UA values for the three heat exchangers of the system in Fig. 11 were calculated by dividing the known rate of heat transfer for each of the three parts of the evaporator (liquid preheating, phase change and vapor superheating; cf. Fig. 5), for the regenerator and for the two parts of the condenser (desuperheating and phase change) by the corresponding logarithmic temperature difference (Incropera \& Dewitt 1996).

Figure 14 presents the summation of these values for a system using $\mathrm{n}$-pentane and $\mathrm{T}_{\text {source,in }}=200{ }^{\circ} \mathrm{C}$. This sum increases monotonically with $\alpha$ (or equivalently with the net power generated by the system). On the other hand, for any given value of $\alpha$, there exists a value of the evaporation pressure which minimises the summation of the UA values. This result is quite important since the size of the heat exchangers is a major component of the capital cost of such a plant. Furthermore, it is also important to note that this optimum pressure is the same one which maximises the value of $\alpha$ (cf. Fig. 13). Qualitatively similar results were obtained for all the working fluids and all the source temperatures. The effect of the working fluid can be judged by comparing the values of $\Sigma U A$ for the respective optimum pressure with the same net power output (same value of $\alpha$ ) and the same source temperature. 
These comparisons indicate that, among the four working fluids under consideration, R123 is the best choice since it requires the smallest heat exchanger and operates at a comparatively low pressure while producing the same net power output.

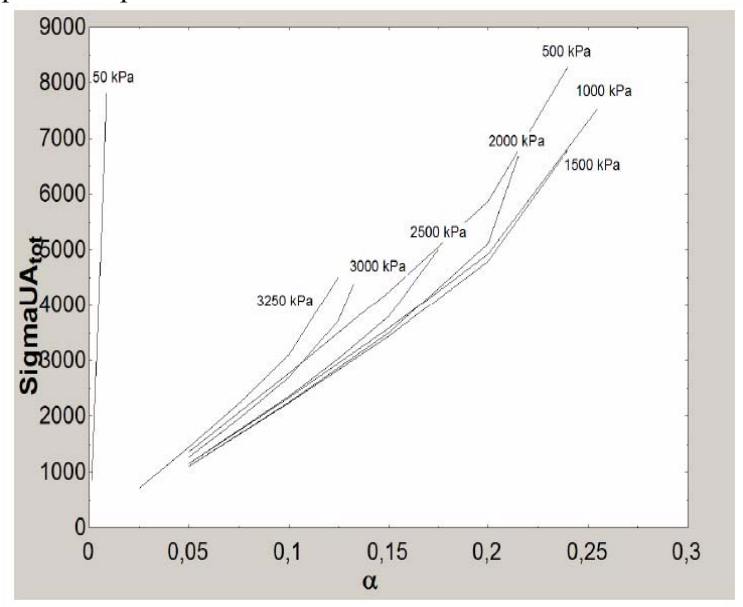

Fig. 14. Total heat exchanger surface (in $\mathrm{kW} / \mathrm{K}$ ) for a system using n-pentane with $\mathrm{T}_{\text {source, in }}=200{ }^{\circ} \mathrm{C}$.

\subsection{Trans-Critical CO2 Cycle}

The performance of a $\mathrm{CO}_{2}$ cycle with heat addition at a super-critical pressure and heat rejection at a fixed subcritical pressure corresponding to a saturation temperature of $15{ }^{\circ} \mathrm{C}$ was analysed using the model described previously for $\mathrm{T}_{\text {source,in }}=100,200$ and $300{ }^{\circ} \mathrm{C}$. For these conditions the maximum power output $\mathrm{W}_{\max }$ (see Eq. 14) is respectively equal to 6090,10450 and $13290 \mathrm{~kW}$. The regenerator effectiveness is fixed at 0.9 .

Figure 15 shows the results of the $1^{\text {st }}$ law analysis for a heat source temperature equal to $200{ }^{\circ} \mathrm{C}$. The dependence of the specific net power output on the maximum pressure of the cycle $\left(p_{1}=p_{6}=p_{5}\right)$ is qualitatively similar to that of the ORC system (Fig. 12). The specific net power output is negligible when the maximum pressure is close to the condensation pressure; then, as $\mathrm{p}_{\max }$ increases, $\mathrm{w}_{\text {net }}$ increases rapidly towards a maximum and then decreases. The value of $\mathrm{w}_{\text {net }}$ does not depend on the presence of the regenerator IHX. On the other hand the thermal efficiency improves considerably with the addition of the regenerator. However this contribution is only possible for values of $p_{\max }$ up to approximately $32.5 \mathrm{MPa}$. Beyond this value the temperature at the outlet of the pump (state 5 in Fig. 11) is higher than the one at the turbine exit (state 2 in Fig. 11). These observations define the acceptable range of values for $p_{\max }$. When the regenerator is not present, as $p_{\max }$ increases, the thermal efficiency increases, reaches a maximum at a fairly high value of $p_{\max }$ and then decreases. On the other hand, for systems which include a regenerator, the efficiency exhibits a clear maximum at a fairly low value of $p_{\max }$. It is important to note that the value of $p_{\max }$ which maximizes $\mathrm{w}_{\text {net }}$ is not the same as the one which maximises $\eta_{\text {therm }}$. However, the maximum values of $\eta_{\text {therm }}$ are only slightly higher than the ones corresponding to maximum $\mathrm{w}_{\text {net }}$. The specific net power output corresponding to maximum $\eta_{\text {therm }}$ is essentially the same as those for maximum $\mathrm{w}_{\text {net }}$ if a regenerator is present but approximately 5\% lower for systems without a regenerator. Furthermore, in order to operate with maximum efficiency the systems without a regenerator require a higher pressure than that for maximum $\mathrm{w}_{\text {net }}$ while the systems with regenerator require a lower pressure than that for maximum $\mathrm{w}_{\text {net }}$. Thus, for $\mathrm{T}_{\text {source,in }}=300{ }^{\circ} \mathrm{C}$ a system with regenerator has a maximum efficiency equal to $25.0 \%$ when $\mathrm{p}_{\max }=27.78$ $\mathrm{kPa}$ and delivers a specific net power of $79.9 \mathrm{~kJ} / \mathrm{kg}$. Design of the system for maximum efficiency instead of maximum $\mathrm{w}_{\text {net }}$ constitutes an interesting option since the lower pressure during heat addition implies a lower cost for the corresponding heat exchanger, pump and turbine. Of course this lower initial investment is countered by the reduction of the specific net power output.

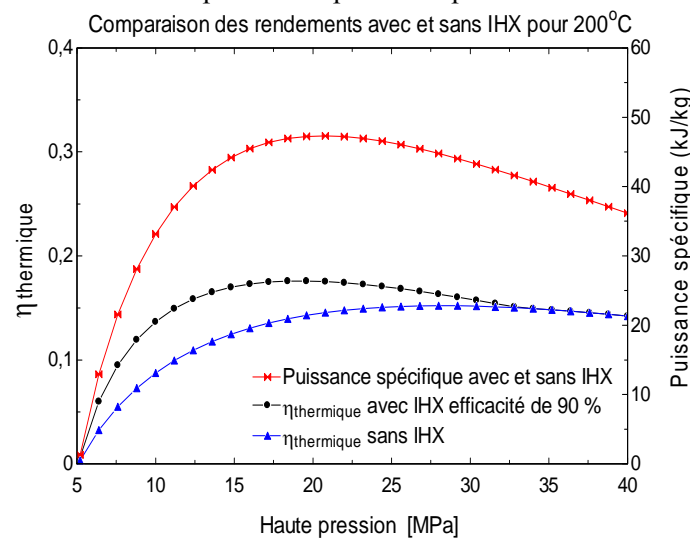

Fig. 15. Specific net power output and thermal efficiency for a $\mathrm{CO}_{2}$ trans-critical cycle (heat source temp $=200{ }^{\circ} \mathrm{C}$, heat sink temp $=10^{\circ} \mathrm{C}$ )

Some of the results of the exergy analysis are shown in Fig. 16. They show that the exergetic efficiency is highest for the same pressure which maximises the thermal efficiency. They also show that the exergetic efficiency increases when $T_{\text {source, in }}$ increases. Finally, they show that the presence of the regenerator, which is operational at low values of $\mathrm{p}_{\max }$, decreases the destruction of exergy; thus, for example, for a heat source temperature of $300^{\circ} \mathrm{C}$ the maximum exergetic efficiency increases from $70 \%$ to $79.7 \%$ with the addition of a regenerator. This beneficial effect is less important for lower heat source temperatures. More details have been presented in another paper (Cayer et al. 2008).

Finally, the size of the three heat exchangers was calculated from the UA values which were determined as explained in the section on ORC systems. However, because the properties of $\mathrm{CO}_{2}$ vary considerably with temperature, particularly during the supercritical heat addition, each heat exchanger was subdivided in 20 sections. The corresponding logarithmic temperature difference was then used to calculate the UA value for each section. The overall heat transfer coefficient $U$ was also calculated for each section by using appropriate correlations. Thus in the evaporator the Petukhov (Incropera \& DeWitt 2002) and KrasnoshchekovProtopopov (Pioro et al. 2004) correlations were used on the air and $\mathrm{CO}_{2}$ sides respectively.

In the condenser the Petukhov correlation was used on the water side and for the single phase part on the $\mathrm{CO}_{2}$ side while the Cavallini correlation (Kakaç \& Liu 2002) was used for the two phase part on the $\mathrm{CO}_{2}$ side. Finally, for the regenerator the Petukhov and KrasnoshchekovProtopopov correlations were used on the hot and cold 
sides respectively. Tube and shell heat exchangers were assumed with external fins on the air (shell) side in the evaporator and the high pressure $\mathrm{CO}_{2}$ flowing in the tubes in the condenser. Typical results in Fig. 17 show that the minimum heat exchanger surface is required by a system without regenerator operating with a maximum pressure slightly lower than the one for maximum efficiency. This minimum heat exchanger surface depends on the value of $\mathrm{T}_{4}$. For the present conditions the smallest possible heat exchanger surface corresponds to $\mathrm{T}_{4}$ close to $90{ }^{\circ} \mathrm{C}$.

Rendement exergétique en fonction de Pmax avec régénérateur

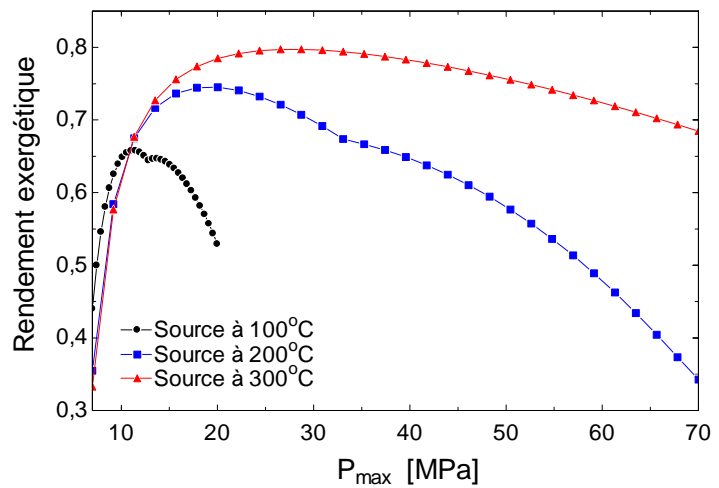

Fig. 16. Exergetic efficiency for a $\mathrm{CO}_{2}$ trans-critical cycle (heat source temp $=200{ }^{\circ} \mathrm{C}$, heat sink temp $=10{ }^{\circ} \mathrm{C}, \alpha=0.15$ )

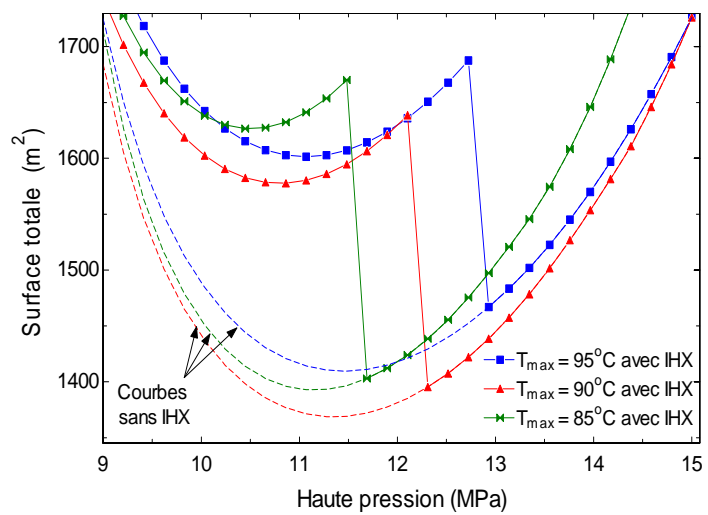

Fig. 17. Total heat exchanger surface for a $\mathrm{CO}_{2}$ system with $\mathrm{T}_{\text {source, in }}=100^{\circ} \mathrm{C}$ and $\alpha=0.2$

\subsection{Rankine Cycle with Ammonia-Water Mixture}

The performance of this cycle was analysed for the conditions defined earlier with the methodology used for the ORC and trans-critical $\mathrm{CO}_{2}$ systems. The performance of the regenerator was specified by setting the temperature at state 3 of Fig. 11 equal to the mean of T2 and T5. In the present case the simulation and presentation of results is more complex because of the influence of an additional independent parameter: the concentration of $\mathrm{NH}_{3}$ in the binary mixture $\left(\mathrm{X}\right.$, in $\mathrm{kg}$ of $\mathrm{NH}_{3}$ per $\mathrm{kg}$ of mixture) which constitutes the working fluid. The calculation procedure has been described elsewhere (Roy et al. 2008).

Figure 18 shows the effect of $p_{\text {ev }}$ and $\mathrm{X}$ on the net power output for $\mathrm{T}_{\text {source, in }}=300{ }^{\circ} \mathrm{C}$. For a value of $\mathrm{p}_{\mathrm{ev}}$ close to the condensation pressure this output is zero but it increases rapidly as $p_{e v}$ increases. However, as $p_{e v}$ increases the liquid content at the turbine outlet (state 2 in Fig. 11) increases as well. This value must not exceed an upper limit (fixed at 5\% in the present study) to avoid problems in the turbine. Therefore $p_{e v}$ is also bound by an upper limit. As seen in Fig. 18, the range of acceptable evaporation pressures increases as $\mathrm{X}$ increases from almost pure water $(\mathrm{X}=0.1)$ to almost pure ammonia $(X=0.975)$. On the other hand the maximum value of the net power output decreases as $\mathrm{X}$ increases. This result indicates that, based on the value of $\mathrm{w}_{\text {net }}$, a system using pure water is more productive for this relatively high heat source temperature. On the other hand, for $\mathrm{T}_{\text {source, in }}$ equal to 200 and $100{ }^{\circ} \mathrm{C}$ the ammonia concentrations generating maximum output are $\mathrm{X}=0.1$ and $X=0.975$ respectively. In fact, for $T_{\text {source, in }}=100^{\circ} \mathrm{C}$ the ammonia mass fraction cannot be lower than approximately $90 \%$ since for lower mass fractions the liquid content at the exit from the turbine would always exceed the adopted maximum allowable value (5\%). This observation explains why pure water $(\mathrm{X}=0)$ can not be used as the working fluid when the heat source temperature is low. It is also important to note that, for $\mathrm{T}_{\text {source, in }}=100{ }^{\circ} \mathrm{C}$ both the maximum net work output and the efficiency increase with the ammonia mass fraction.

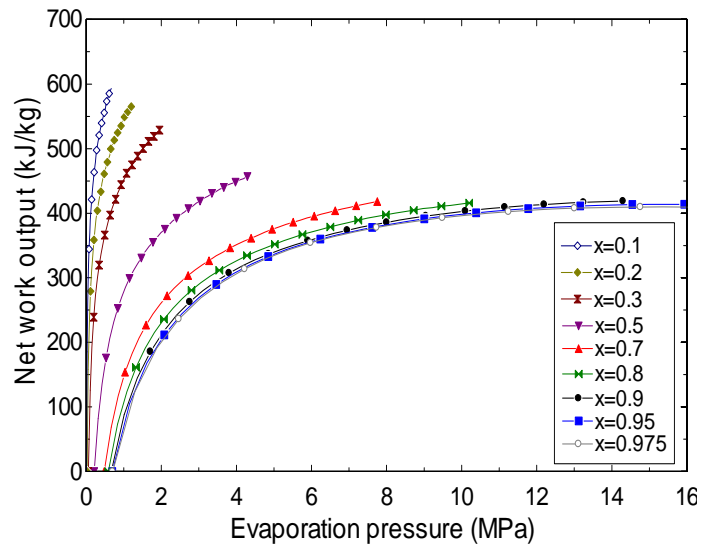

Fig. 18. Net power output for an ammonia/water cycle with $\mathrm{T}_{\text {source,in }}=300^{\circ} \mathrm{C}$

Figure 19 shows the thermal efficiency of such a cycle. In particular, it illustrates the improvement of $\eta_{\text {therm }}$ produced by the presence of a regenerator. Furthermore, it shows that a regenerator with the previously specified characteristics can not be used over the entire range of acceptable evaporation pressures since it may lead to physically impossible numerical results (negative pinch). Such results were not obtained in the two previously analyzed cases (ORC and trans-critical $\mathrm{CO}_{2}$ cycles) and are due to the very different properties of the hot and cold binary mixtures present in the regenerator. The positive effect of the regenerator on $\eta_{\text {therm }}$ decreases with $T_{\text {source,in }}$. Thus, for a heat source temperature of $100{ }^{\circ} \mathrm{C}$ this improvement is less than $5 \%$.

Figure 20 shows the exergy efficiency of the ammonia/water Rankine cycle without regenerator for a heat source temperature of $300{ }^{\circ} \mathrm{C}$. For a fixed ammonia mass fraction, $\eta_{\mathrm{ex}}$ increases with $\mathrm{P}_{\text {evap. }}$. The influence of the ammonia mass fraction is however quite complex. For low values of this parameter $(X \leq 0.5)$ the maximum value of $\eta_{\text {ex }}$ decreases as $X$ increases. Specifically, pure water $(\mathrm{X}=0)$ has a higher exergy efficiency than weak ammonia-water mixtures. This rather surprising result is due to the fact that the irreversibility in the condenser increases as $\mathrm{X}$ increases due to the fact that the chosen 
temperature variation in the coolant $\left(2^{\circ} \mathrm{C}\right)$ is very small and that, therefore, the best matching of the temperature profiles therein is obtained for a pure working fluid. On the other hand, for rich mixtures $(X \geq 0.8)$ the maximum exergy efficiency increases when the ammonia mass fraction in the mixture increases. This is due to the fact that for these concentrations the heat source temperature is higher then the critical temperature of the mixture. For the high evaporation pressures which maximise $\eta_{\mathrm{ex}}$ the mixture in the cycle is in supercritical state at the vapour generator outlet. As a consequence, the temperature profile of the heat source has a much better match with the corresponding profile of a very rich mixture. As mentioned earlier, a better thermal match results in a decrease of the irreversibility in the heat exchangers. Consequently, the exergy efficiency increases as shown in Fig. 20. Overall, for $\mathrm{T}_{\text {source, in }}=300{ }^{\circ} \mathrm{C}$, a cycle with pure ammonia has a superior exergy efficiency than a cycle with pure water.

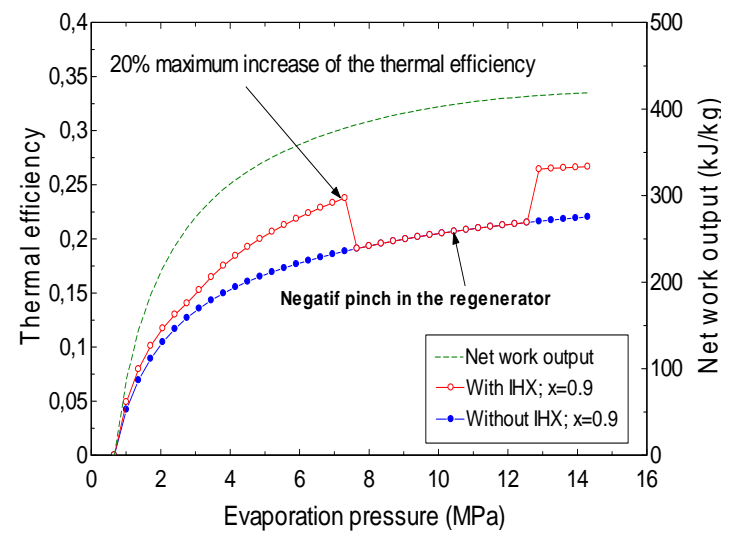

Fig. 19. Thermal efficiency and net power output for an ammonia/water cycle $\left(\mathrm{T}_{\text {source, }}=300{ }^{\circ} \mathrm{C}, \mathrm{X}=0.9\right)$

The calculation of the heat exchangers' surface was carried out as in the case of the $\mathrm{CO}_{2}$ cycle. Shell and tube heat exchangers were chosen with external fins on the air (shell) side in the evaporator and on the ammonia/water (shell) side in the condenser. They were subdivided into approximately 50 sections to account for the variable properties of the working fluid with temperature. The value of UA was calculated for each section from the corresponding logarithmic mean temperature difference and the overall heat transfer coefficient $U$ was also calculated for each section as follows. In the evaporator the Petukhov correlation (Incropera \& DeWitt 2002) was used on the gas side and for the single phase part on the ammonia/water side while a fixed value of $10 \mathrm{~kW} / \mathrm{m}^{2} \mathrm{~K}$ (also applied by Stecco \& Desideri 1992 and Thorin 2001) was used for the two phase part on the ammonia/water side. In the condenser the Petukhov correlation was used on the water side and for the single phase part on the ammonia/water side while the correlation for condensation on the outside of a horizontal tube was used for the two phase part on the ammonia/water side (Kakaç \& Liu 2002). Finally, for the regenerator the Petukhov and condensation correlations were used on the hot and cold sides respectively.

Figure 21 shows typical results of these calculations. The existence of an optimum evaporation pressure which minimises the total surface of the two heat exchangers (evaporator and condenser) is quite evident.
The existence of such an optimum evaporation pressure is quite significant from an economic point of view since the cost of the heat exchangers increases with their surface. The fact that this surface increases as $p_{e v}$ becomes very small or very large is due to the corresponding decrease of $\mathrm{w}_{\text {net }}$ and the resulting increase of the working fluid's mass flow rate to preserve a constant net power output (constant $\alpha$ ). It should be noted that the addition of a regenerator does not change significantly the values of the heat exchangers' surface since the additional surface of the regenerator is compensated by the reduction of the evaporator's surface.

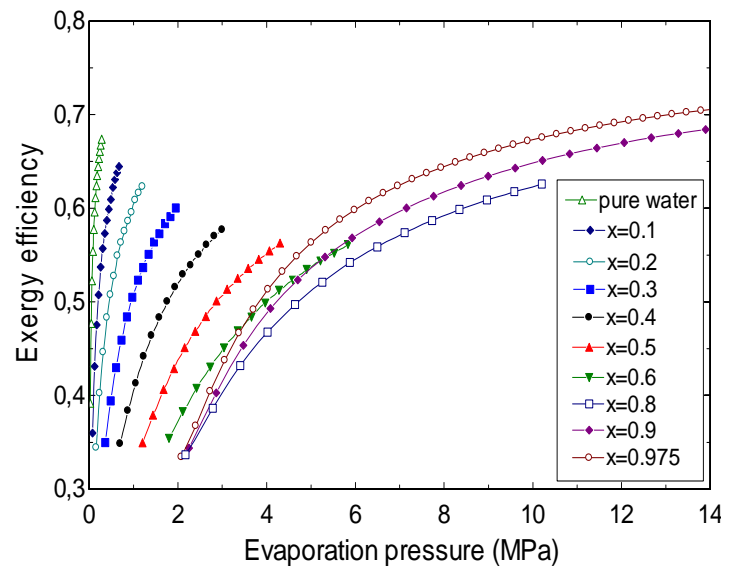

Fig. 20. Exergetic efficiency for an ammonia/water cycle (heat source $300{ }^{\circ} \mathrm{C}$, heat sink $10^{\circ} \mathrm{C}, \alpha=0.15$ )

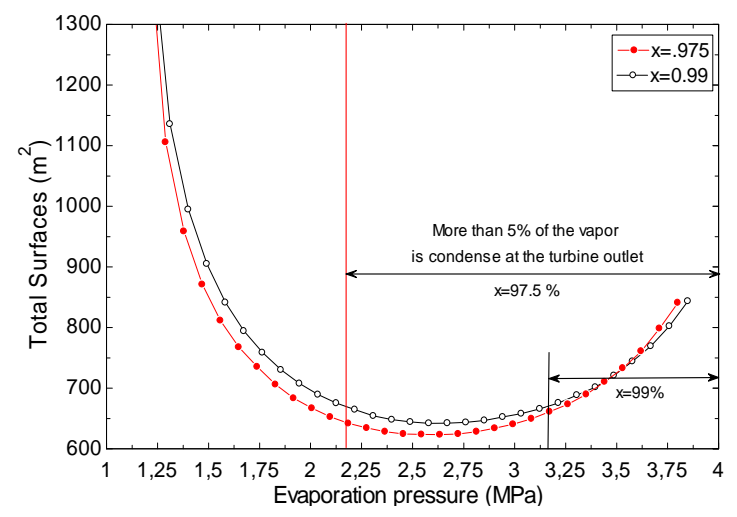

Fig. 21. Total surface of heat exchangers for an ammonia/water cycle (heat source temp $=100{ }^{\circ} \mathrm{C}$, heat sink temp $=10^{\circ} \mathrm{C}, \alpha=0.15$ )

\section{Conclusions}

Power plants using conventional processes (compression of a liquid, expansion of a vapor, heat transfer at essentially constant pressure) and unconventional fluids (refrigerants, $\mathrm{CO}_{2}$, binary mixtures) have a significant potential for the valorization of low and medium temperature renewable energy sources as well as waste heat from industrial, commercial or institutional installations. This review paper has described some prototypes of such power plants and has summarized some of the relevant scientific and technical literature. An analysis based on the first and second laws of thermodynamics and basic heat transfer relations was used 
to illustrate the operational limits and performance characteristics of these power plants. Thus, for a heat source temperature of $100^{\circ} \mathrm{C}$ :

- The maximum value of the specific net power output and the corresponding pressure in the vapor generator are 32.0 $\mathrm{kJ} / \mathrm{kg}$ and $700 \mathrm{kPa}$ for R123, $41.5 \mathrm{~kJ} / \mathrm{kg}$ and $600 \mathrm{kPa}$ for $\mathrm{R} 141 \mathrm{~b}, 69.7 \mathrm{~kJ} / \mathrm{kg}$ and $525 \mathrm{kPa}$ for n-pentane, $65.7 \mathrm{~kJ} / \mathrm{kg}$ and $1375 \mathrm{kPa}$ for n-butane, $18.8 \mathrm{~kJ} / \mathrm{kg}$ and $11.48 \mathrm{MPa}$ for $\mathrm{CO}_{2}, 127.5 \mathrm{~kJ} / \mathrm{kg}$ and $2.2 \mathrm{MPa}$ for ammonia/water mixture with $\mathrm{X}=97.5 \%$ and, finally, $150.5 \mathrm{~kJ} / \mathrm{kg}$ and $3.2 \mathrm{MPa}$ for ammonia/water mixture with $\mathrm{X}=99 \%$.

- The maximum values of $\alpha$ and the corresponding pressure in the vapour generator are 0.22 and $300 \mathrm{kPa}$ for R123, 0.22 and $200 \mathrm{kPa}$ for R141b, 0.215 and $200 \mathrm{kPa}$ for n-pentane, 0.215 and $700 \mathrm{kPa}$ for n-butane, 0.291 and $12.96 \mathrm{MPa}$ for $\mathrm{CO}_{2}, 0.22$ and $2.2 \mathrm{MPa}$ for ammonia/water mixture with $\mathrm{X}=97.5 \%$ and, finally, 0.22 and $2.4 \mathrm{MPa}$ for ammonia/water mixture with $X=99 \%$.

- The minimum values of the total heat exchanger area for $\alpha=0.2$ and the corresponding pressure and temperature in the vapour generator are $1591 \mathrm{~m}^{2}, 7.62 \mathrm{MPa}$ and $87.1^{\circ} \mathrm{C}$ for ethane; $1217 \mathrm{~m}^{2}, 3.96 \mathrm{MPa}$ and $83.7^{\circ} \mathrm{C}$ for R125; $1369 \mathrm{~m}^{2}$, $11.35 \mathrm{MPa}$ and $89.9^{\circ} \mathrm{C}$ for $\mathrm{CO}_{2} ; 995 \mathrm{~m}^{2}, 2.2 \mathrm{MPa}$ at $95^{\circ} \mathrm{C}$ for ammonia/water mixture with $\mathrm{X}=97.5 \%$ and, finally, $1006 \mathrm{~m}^{2}, 2.4 \mathrm{MPa}$ at $95^{\circ} \mathrm{C}$ for ammonia/water mixture with $\mathrm{X}=99 \%$.

These results indicate that for this very low heat source temperature the trans-critical $\mathrm{CO}_{2}$ cycle produces by far the highest net power output $(\alpha=0.29$ while all the other cases give $\alpha \leq 0.22$ ) but operates at much higher pressures and requires a larger total heat exchanger area than the ammonia/water Rankine cycle.

\section{ACKNOWLEDGMENT}

This project is part of the R\&D program of the NSERC Chair in Industrial Energy Efficiency established in 2006 at Université de Sherbrooke. The authors acknowledge the support of the Natural Sciences \& Engineering Research Council of Canada, Hydro Québec, Alcan International Ltd and CANMET Energy Technology Center.

\section{REFERENCES}

Cayer E., N. Galanis, M. Désilets and H. Nesreddine (2008). Étude thermodynamique d'un cycle transcritique au dioxyde de carbone pour la récupération de chaleur de basse température. Can. Soc. of Mech. Eng. Forum, Ottawa Canada.

Chen Y., P. Lundqvist, A. Johansson and P. Platell (2006). A comparative study of the carbon dioxide transcritical power cycle compared with an organic Rankine cycle with R123 as working fluid in waste heat recovery, Applied Thermal Engineering 26 (17-18), 2142-2147.

DiPippo R. (2004). Second law assessment of binary plants generating power from low-temperature geothermal fluids. Geothermics 33(5), 565-586.

Dostal V. (2004). A supercritical carbon dioxyde cycle for next-generation nuclear reactors, $\mathrm{PhD}$ thesis, MIT.
Duffy D. (2005). Better cogeneration through chemistry: the organic Rankine cycle. Distributed Energy (Nov.Dec. 2005 Technology review).

El-Sayed Y. and M. Tribus (1985). A theoretical comparison of the Rankine and Kalina cycles. ASME Winter Annual Meeting.

Goswami D.Y. (1995). Solar thermal power: status of technologies and opportunities for research. Proc. $2^{\text {nd }}$ ASME-ISHMT Heat and Mass Transfer Conf. TataMcGraw Hill, New Delhi India, 57-60.

Goswami D.Y. and F. Xu (1999). Analysis of a new thermodynamic cycle for combined power and cooling using low and mid temperature solar collectors. ASME Journal of solar energy engineering 121, 91-97.

Gu Z. and H. Sato (2002). Performance of supercritical cycles for geothermal binary design. Energy conversion \& management 43, 961-971.

Hjartarson H., R. Maack and S. Johannesson (June 2005). Husavic energy multiple use of geothermal energy. GHC bulletin, 7-13.

Ibrahim O.M. and S.A. Klein (1996). Absorption power cycles. Energy 21(1), 21-27.

Incropera F.P. and D.P. DeWitt (2002). Fundamentals of Heat and Mass Transfer. $5^{\text {th }}$ ed., J. Wiley, New York.

International Energy Agency (2007). Key World Energy Statistics.

Kakaç S. and Liu H. (2002). Heat Exchangers: Selection, Rating and Thermal Design, New York, 2nd ed. CRC Press New York.

Kalina A.I. (1983). Combined cycle and waste heat recovery power systems based on a novel thermodynamic energy cycle using low-temperature heat for power generation. ASME paper 83-JPGCGT-3, Fairfield NJ, USA.

Kalina A.I. (1991). Kalina cycles and system for directfired power plants, ASME second law analysisindustrial and environmental applications 25, 41-47.

Kalina A.I. and H.M. Leibowitz (1989). Application of the Kalina cycle technology to geothermal power generation. Geothermal Resources Council Transactions 13, 605-611.

Kalina A.I., H.M. Leibowitz, D. Markus and R. Pelletier (1991). Further technical aspects and economics of a utility-size Kalina bottoming cycle 365, 1-7.

Kane M., D. Larrain, D. Favrat and Y. Allani (2003). Small hybrid solar power system. Energy 28, 14271443.

Kato Y., T. Nitawaki and Y. Muto (2004). Medium temperature carbon dioxide gas turbine reactor. Nuclear Engineering and Design 230, 195-207. 
Klein S.A. (2007). Engineering Equation Solver EES Academic Commercial V7.933, McGraw Hill. See also https://www.fchart.com.

Maloney J.D. and R.C. Robertson (1953). Thermodynamic study of ammonia-water heat power cycles. ORNL Report CF-53-8-43, Oak Ridge TN, USA.

Obernberger I., P. Thornhofer and E. Reisenhofer (2002). Description and evaluation of the new $1000 \mathrm{kWel}$ organic Rankine cycle process integrated in the biomass CHP plant in Lienz, Austria. Euroheat \& Power 10.

Pernecker G. and S. Uhlig (2002, March). Low-enthalpy power generation with ORC turbogenerator: the Altheim project, upper Austria. GHC Bulletin. See also http://www.geothermie.de/gte/gte3637/altheim_gaia.htm.

Pioro I.L, H.F. Khartabil and R.B. Duffey (2004). Heat transfer to supercritical fluids flowing in channels empirical correlations (survey), Nuclear Engineering and Design 230, 69-91.

Prabhu E. (2006). Solar trough organic Rankine electricity system (STORES) Stage 1: Power plant optimization and economics. available at http://www.nrel.gov/docs/fy06osti/39433.pdf.

Rogers G. and Y. Mayhew (1992). Engineering Thermodynamics, Work and Heat Transfer. $4^{\text {th }}$ ed. Harlow Longman Scientific \& Technical.

Roy P., N. Galanis, M. Désilets and H. Nesreddine (2008). First and second law analysis of an ammonia/water mixture Rankine cycle with low temperature heat sources. Can. Soc. of Mech. Eng. Forum, Ottawa, Canada.

Saleh B., G. Koglbauer, M. Wendland and J. Fischer (2007). Working fluids for low-temperature organic Rankine cycles. Energy 32, 1210-1221.

Sawalha S. (2005, August). Using CO2 in supermarket refrigeration. ASHRAE Journal, 26-30.

Stecco S. and U. Desideri (1992). Considerations on the design principles for a binary mixture heat recovery boiler. ASME-Journal of engineering for gas turbines and power 114, 701-706.

Stricker S., T. Strack, L.F. Monier and R. Clayton (2006). Market report on waste heat and requirements for cooling and refrigeration in Canadian industry. CANMET Energy Technology Centre.

Tamm G. and D.Y. Goswami (2003). Novel combined power and cooling thermodynamic cycle for low temperature heat sources, Part II: experimental investigation. ASME Journal of solar energy engineering 125, 223-229.

Thorin E. (2001). Thermophysical properties of ammoniawater mixtures for prediction of heat transfer areas in power cycles. International Journal of Thermophysics 22(1), 201-214.
US Environmental Protection Agency (2006). Global warming potentials of ODS substitutes. Washington DC. See also www.epa.gov/docs/ozone/geninfo/gwps.html

Wright S.A. (2007). Supercritical Brayton Cycle Nuclear Power System Concepts. American Institute of Physics Conf Proceedings 880, 597-604.

Yamaguchi H., X.R. Zhang, K. Fujima, M. Enomoto and N. Sawada (2006). Solar energy powered Rankine cycle using supercritical CO2. Applied Thermal Engineering 26, 2345-2354.

Yamamoto T., T. Furuhata, N. Arai and K. Mori (2001). Design and testing of the organic Ranking Cycle. Energy 26, 239-251.

Zhang X.R., H. Yamaguchi, K. Fujima, M. Enomoto and N. Sawada (2007). Theoretical analysis of a thermodynamic cycle for power and heat production using supercritical carbon dioxide. Energy 32(4), 591-599. 